perspectivas

a debate El marco legal para la protección del patrimonio paleontológico. ¿Qué pasa en tu comunidad?

| coordina Eloísa Bernáldez Sánchez

\title{
La conservación del patrimonio paleontológico en Canarias
}

Esther Martín González | conservadora de paleontología y geología del Museo de Ciencias Naturales de Tenerife

URL de la contribución <www.iaph.es/revistaph/index.php/revistaph/article/view/4142>

Al encontrarnos en islas volcánicas oceánicas que tienen una edad tan moderna como 23 millones de años, en el caso de Fuerteventura, se piensa que nuestro patrimonio paleontológico es pobre e, incluso, inexistente. Sin embargo, poseemos fósiles de ammonites de más de 150 millones de años, depositados en el fondo oceánico del primigenio océano Atlántico y que debido a las fuerzas tectónicas afloran en escasos lugares. $Y$ huevos de aves no voladoras de 4,5 millones de años que fosilizaron en un banco de dunas al norte de Lanzarote. O importantísimos depósitos de improntas vegetales que nos indican la evolución de la vegetación de las islas. Y también impresionantes playas fósiles con gran cantidad de especies marinas, que no solamente nos indican los cambios del nivel del mar, sino también tremendos eventos de alta energía (tsunamis). Nuestro registro fósil no es muy diverso, pero la fragmentación y fragilidad de los territorios insulares hace que tenga un incuestionable valor científico y patrimonial. Para los paleontólogos que trabajamos en las islas es primordial conservar, al menos, un tipo de yacimiento en cada una de las islas, porque constituye una evidencia única de la historia evolutiva de cada una de ellas.

En el caso de la Comunidad Autónoma de Canarias, el patrimonio paleontológico queda legalmente protegido por la Ley 4/99 de Patrimonio Histórico de Canarias, con la definición de bienes de interés cultural (BIC) en la categoría de zona paleontológica, en el caso de yacimientos singulares o de gran importancia científica, y la inclusión de otros menos importantes en las cartas paleontológicas insulares (caso de Fuerteventura) o municipales (municipio de Arucas). La otra ley que permite la protección de los yacimientos paleontológicos es la Ley del Suelo y Espacios Naturales Protegidos de Canarias, bajo la figura de monumentos naturales, pero hasta el momento no existe ningún yacimiento paleontológico recogido como tal. Ocurre al contrario que con la legislación de patrimonio histórico, existiendo en este momento un total de nueve yacimientos declarados como BIC en las diferentes islas del archipiélago.

El anteproyecto de la Ley de Patrimonio Cultural de Canarias que se está promoviendo en estos momentos desde la Dirección General de Patrimonio Histórico del Gobierno de Canarias plantea que el patrimonio paleontológico se elimine de su ámbito de protección, pasando a estar únicamente protegido por la legislación de ordenación territorial regional, la discutida Ley del Suelo y Espacios Naturales Protegidos de Canarias. Sin embargo, no se ha detallado cómo se haría la transposición de aquellos yacimientos paleontológicos declarados $\mathrm{BIC}$, se supone que, por su importante valor patrimonial, a la figura de monumento natural. Hay que señalar que solo en el caso de Lanzarote existe coincidencia entre BIC paleontológico y monumento natural declarado previamente, Los Ajaches, que incluye parte del BIC Punta de Garajao a Punta de Papagayo. En Canarias existen declarados 52 espacios naturales en la categoría de monumento natural, y solo el de Ajuy considera el interés paleontológico entre los motivos fundamentales para su protección. Hay que añadir a esto que las normas de conservación, las normas de protección de los monumentos naturales, entraron en vigor en 2005, a pesar de ser declarado como tal en 1987. Respecto a esto se debe hacer hincapié que en el archipiélago no se ha declarado ningún espacio natural protegido desde 1987, por la Ley 12/1987, de 19 de junio, de Declaración de Espacios Naturales, modificados en su denominación por la Ley 12/1994, de 19 de diciembre, de Espacios Naturales de Canarias.

Para gestionar un recurso es imprescindible identificarlo y conocerlo. Por ello es necesario realizar los inven- 


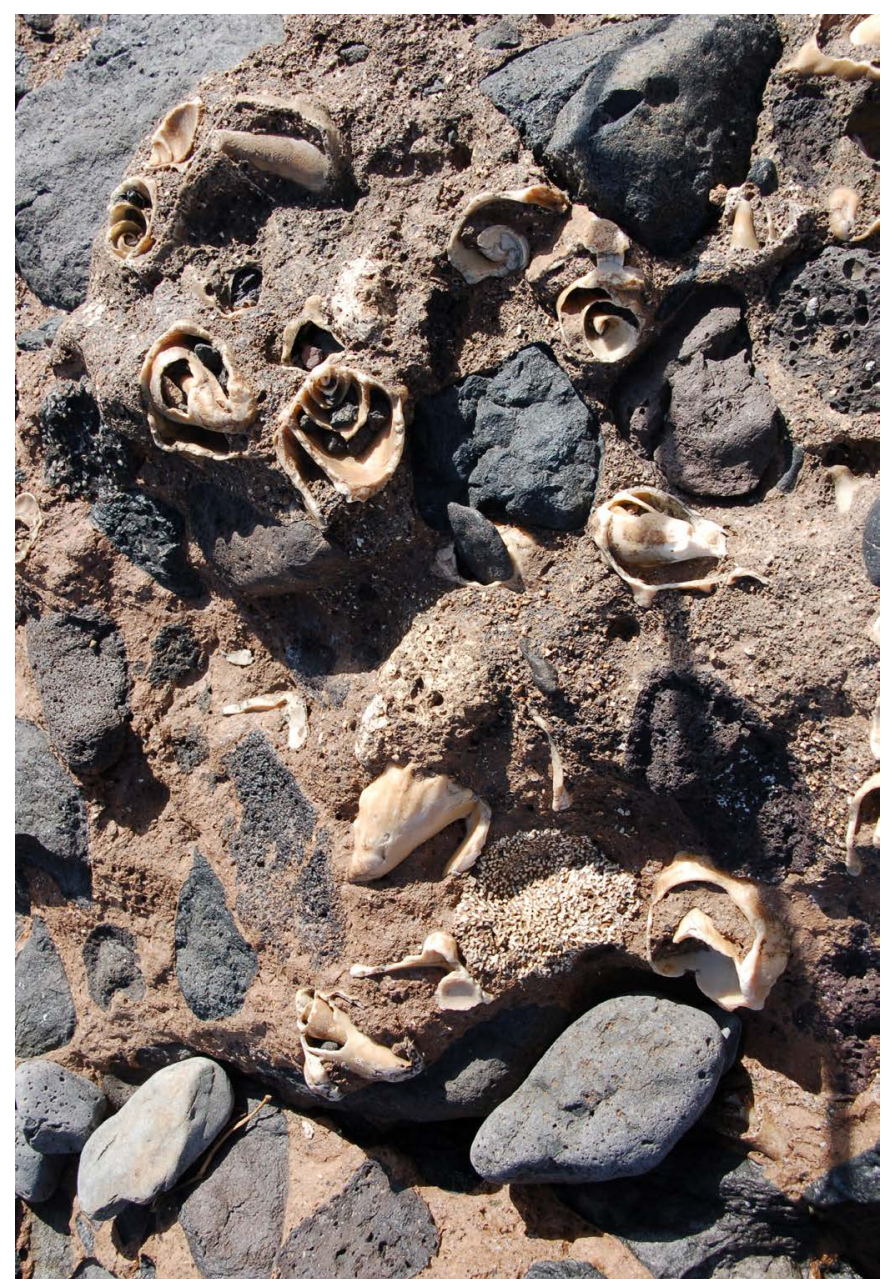

Conchas de Persististrombus latus en el afloramiento de Matas Blancas, BIC en Fuerteventura | foto Esther Martín González

tarios de los elementos que conforman el patrimonio paleontológico, lo que implica la identificación, localización y clasificación de los lugares de interés paleontológico. Estos inventarios no existen en la legislación del patrimonio natural de Canarias, pero sí en el caso de las cartas paleontológicas de Fuerteventura y Lanzarote y algunos términos municipales como Arucas (en Gran Canaria) y Granadilla (Tenerife), incorporándolos a los Planes Insulares de Ordenación del Territorio. Esto proporciona ciertas medidas de conservación a los yacimientos paleontológicos, de modo que se obligue a las administraciones públicas a autorizar determinadas obras en estos lugares de especial riqueza patrimonial, estableciendo aquellas medidas correctoras adecuadas y de obligado cumplimiento, como se hace con el patrimonio arqueológico.

Sin embargo, al igual que ocurre en otras comunidades autónomas, el patrimonio paleontológico canario sigue estando sumido en un halo de indefensión jurídica. Su conservación y protección es una acción de presente, no de futuras legislaturas. Hasta que la Ley 42/2007 de Biodiversidad y Patrimonio Natural no se transponga a la legislación canaria, es imposible e inaudito realizar un cambio tan drástico como el que se propone. La declaración de los yacimientos paleontológicos como monumentos naturales es inviable tal y como se entienden actualmente; a ello hay que sumar la dilación en el tiempo de la aprobación de las normas de conservación de estos espacios protegidos. Urge, por tanto, el desarrollo de una legislación específica sobre este tema que permita hacer llegar a las generaciones futuras aquellos vestigios que les facilite comprender de dónde deriva la biodiversidad que los rodea. 